\title{
A COMPREHENSIVE RESISTIVITY AND GPR INVESTIGATION IN A ROMAN THERMAL SITE.
}

\author{
Fernando E.R. Almeida \\ Department of Geosciences, University of Aveiro, 3800 Aveiro, Portugal
}

The village of Vizela, Northwest of Portugal, has a important Roman thermal site. Excavations related with sewage system development detected a Roman occupation level at the level of $99 \mathrm{~m}$, that was in danger of being damaged. In order to design a suitable sewage system that would preserve the Roman findings a Geophysical survey was carried out.

The geophysical survey comprised GRP (Ground Penetrating Radar) and resistivity investigations. GPR measurements were obtained using a Pulse eKKo IV radar system with a center frequency of $100 \mathrm{MHz}$, a two meters antenna separation, two meters line separation and sampling five points per meter. It was found that the roman occupation level is locally related with the first and strongest detected GPR reflection. Software was developed in order to enhance these signals and improve data display and analysis. Thus data were obtained and transformed to ASCII format and than processed for radargram spatial presentation. The signal low (dewowing) and high frequencies components were extracted. Signal time zero detection was done using a maximumminimum logic and time position of the highest reflection was also detected. Once the time zero was determined the ground wave first instant was determined. Finally, using a CMP estimated velocity the intensities of the processed signal were projected in a depth level base. 
This type of processing makes the signals corresponding to near surface structures clearer than those obtained with standard techniques as it can be seen by comparing a selected profile in Figs. 1 (standard) and 2 (spatial presentation with local levels). Thus this particular type of processing is very important when trying to identify occupation levels.

Fig. 3 shows the radar depths of the most important reflector, while Fig. 4 represents the corresponding radar level surface related to the topographic leveling.

The Resistivity survey was carried out using a personal Tripotencial Wenner multicable system, based on the work of Carpenter and Habberjam (1956), to detect antropic structures (Roman buildings, underground thermal conduct) and thermal springs. The resistivity maps, Figs. 5 and 6 , obtained with Wenner tripotencial beta array spacings of one and two meters, show resistivity alignments similar to the expected Roman urban pattern.

Once the resistivity alignments are plotted they are shown to coincide with the detected radar features above the 99 metre occupation level, and thus a clear image of the subsurface is obtained.

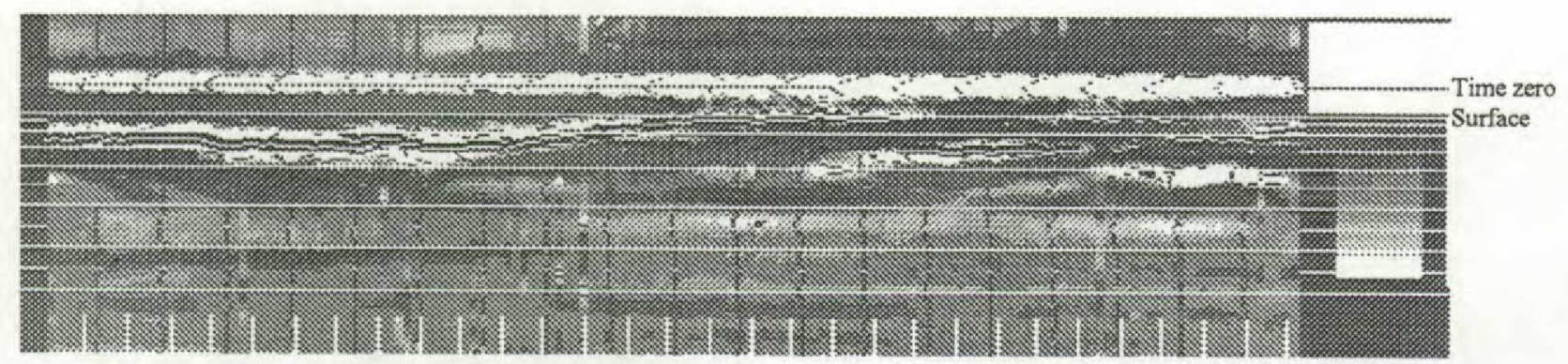

Fig.1: Two way time standard processing for time zero detection, filtering (dewowing low frequency, and high components removal). Depth vertical scale for velocity $0.125 \mathrm{~m} / \mathrm{nsec}$; lateral tie lines corresponds to half meter; horizontal ties lines corresponds to one meter.

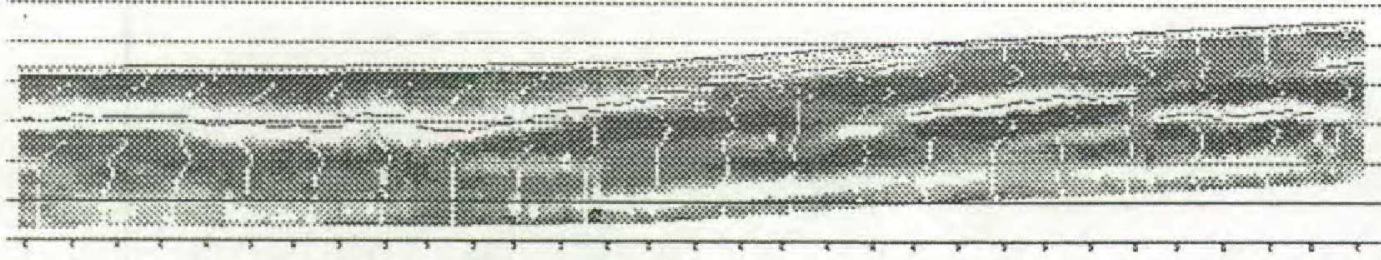

Fig2: Depth projection traces refereed to the surface with cropping of time before first ground wave arrival predicted with $0.125 \mathrm{~m} / \mathrm{nsec}$ constant velocity model. Horizontal and vertical ties lines corresponds to one meter. Time variable gain were also applied. 


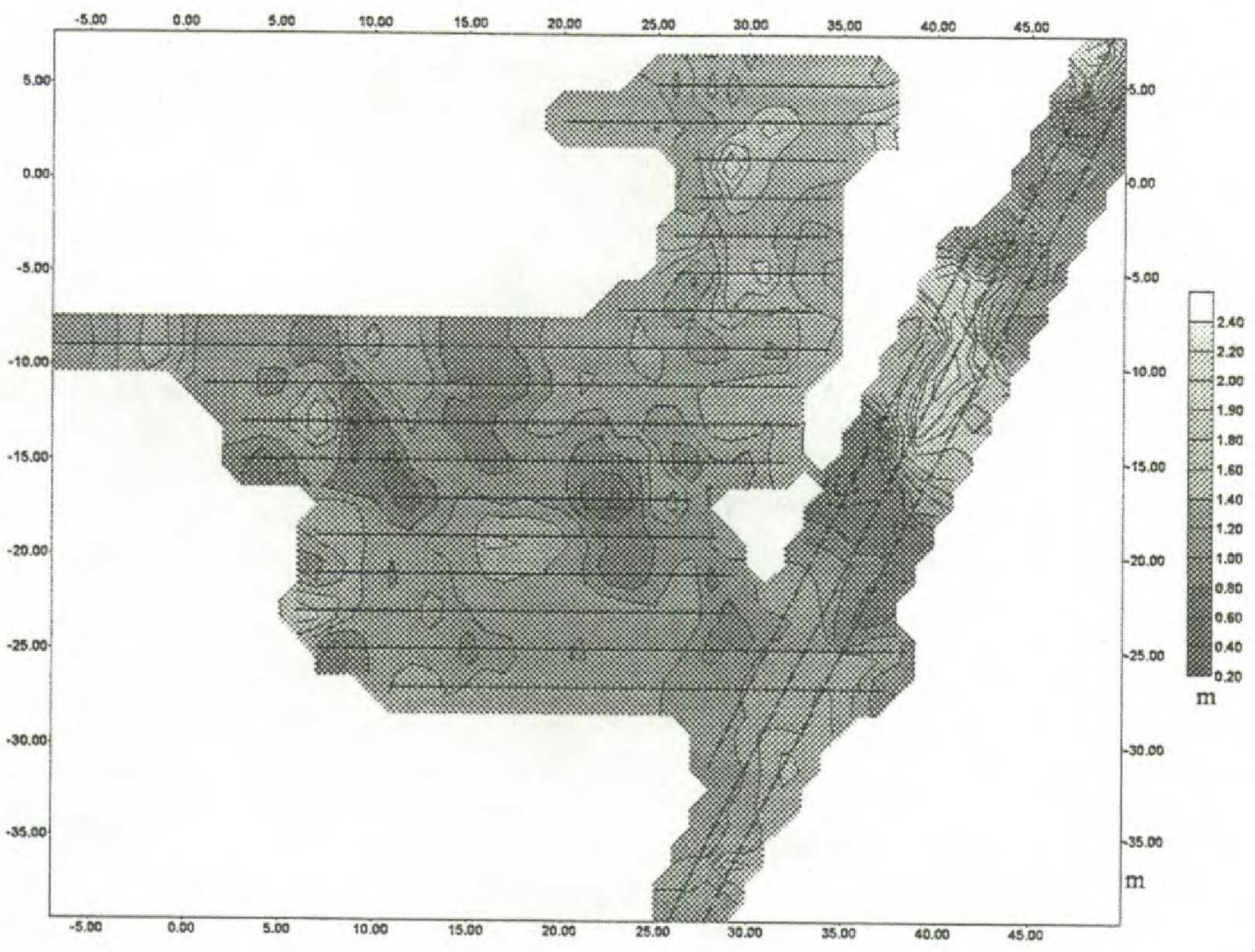

Fig.3 :Radar depth surface of the most important reflector.

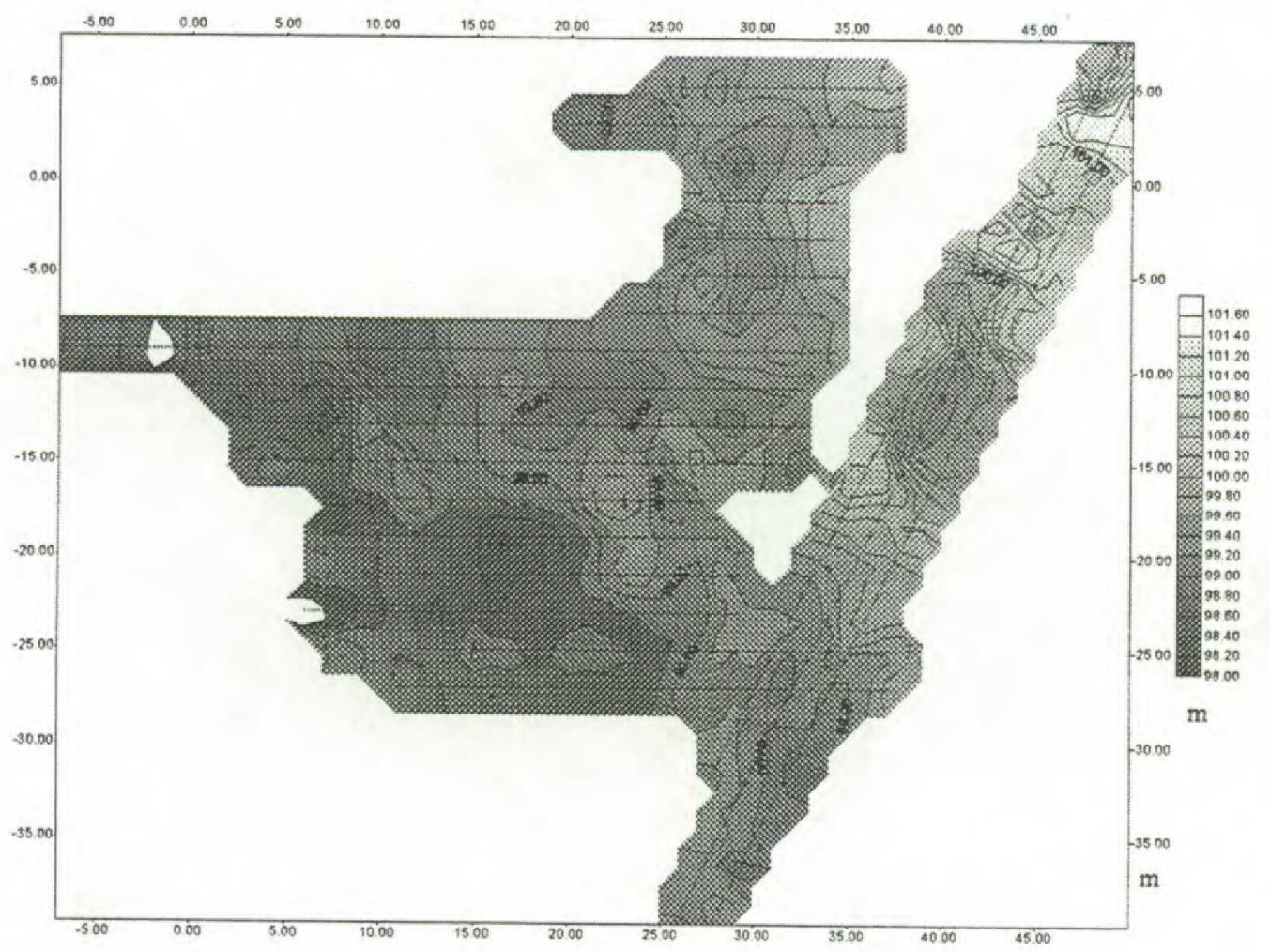

Fig 4: Radar surface of most important reflector . 


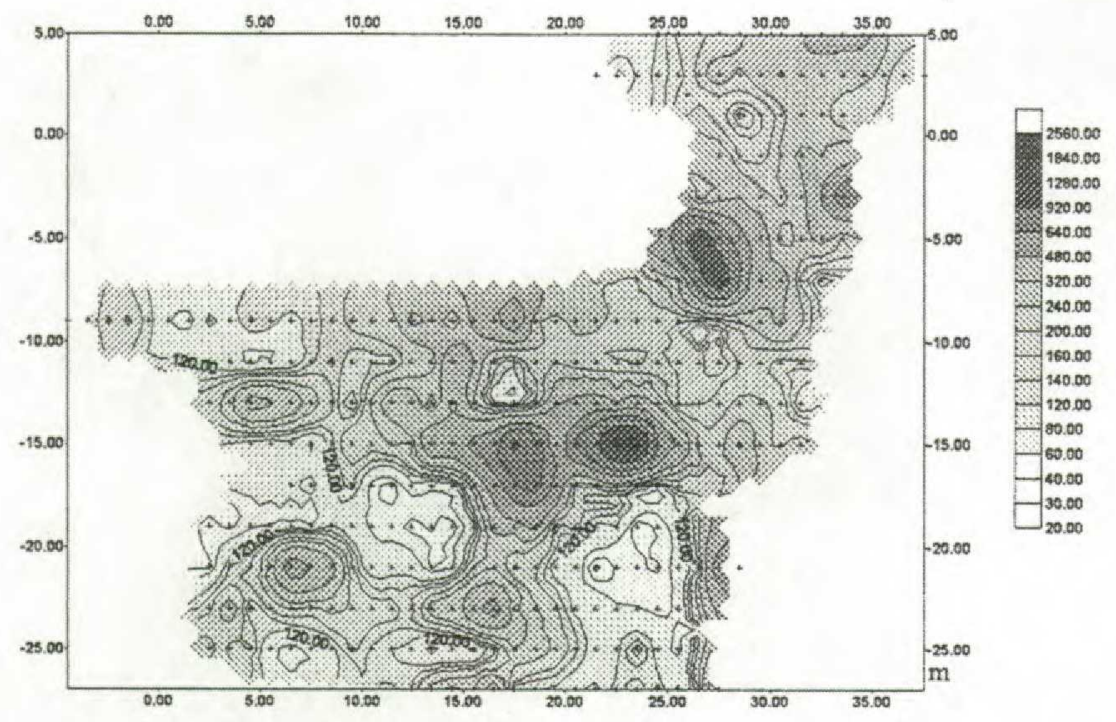

Fig5: Resistivity map (Wenner beta array , $\mathrm{a}=1 \mathrm{~m}$, values in ohm.m)

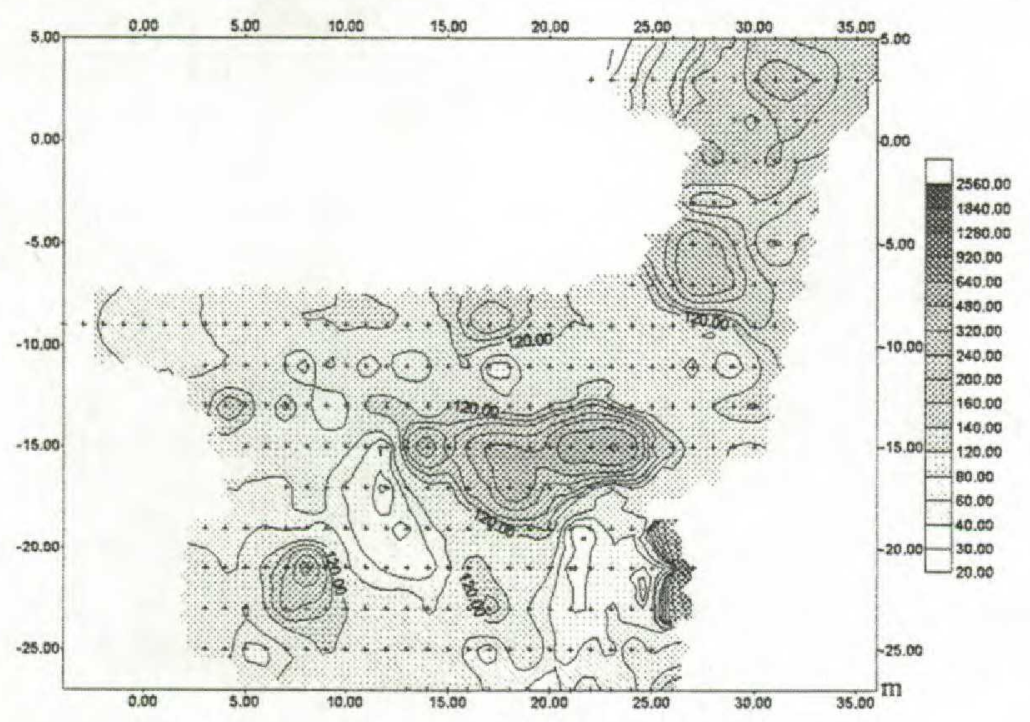

Fig.6: Resistivity map (Wenner beta array , $a=2 \mathrm{~m}$, values in ohm.m)

\section{References}

Carpenter, E. C. e Habberjam, G. M. 1956. A Tri-Potencial Method of resistivity Prospecting. Geophysics, 21;455-469. 